\title{
A nonsense polymorphism in the protein Z-dependent protease inhibitor increases the risk for venous thrombosis
}

Javier Corral, Rocio González-Conejero, Jose Manuel Soria, Jose Ramón González-Porras, Elena Pérez-Ceballos, Ramón Lecumberri, Vanessa Roldán, Juan Carlos Souto, Antonia Miñano, David Hernández-Espinosa, Ignacio Alberca, Jordi Fontcuberta and Vicente Vicente

Updated information and services can be found at:

http://bloodjournal.hematologylibrary.org/content/108/1/177.full.html

Articles on similar topics can be found in the following Blood collections

Clinical Trials and Observations (3886 articles)

Hemostasis, Thrombosis, and Vascular Biology (2494 articles)

Information about reproducing this article in parts or in its entirety may be found online at:

http://bloodjournal.hematologylibrary.org/site/misc/rights.xhtml\#repub_requests

Information about ordering reprints may be found online at:

http://bloodjournal.hematologylibrary.org/site/misc/rights.xhtml\#reprints

Information about subscriptions and ASH membership may be found online at:

http://bloodjournal.hematologylibrary.org/site/subscriptions/index.xhtml

Blood (print ISSN 0006-4971, online ISSN 1528-0020), is published weekly by the American Society of Hematology, 2021 L St, NW, Suite 900, Washington DC 20036.

Copyright 2011 by The American Society of Hematology; all rights reserved. 


\section{A nonsense polymorphism in the protein Z-dependent protease inhibitor increases the risk for venous thrombosis}

Javier Corral, Rocio González-Conejero, Jose Manuel Soria, Jose Ramón González-Porras, Elena Pérez-Ceballos, Ramón Lecumberri, Vanessa Roldán, Juan Carlos Souto, Antonia Miñano, David Hernández-Espinosa, Ignacio Alberca, Jordi Fontcuberta, and Vicente Vicente

The protein Z-dependent protease inhibitor (ZPI) is a hemostatic serpin with anticoagulant activity. As for antithrombin, deficiency of ZPI could have relevant thrombotic consequences. We have studied 6 genetic modifications affecting the ZPI gene, identifying 5 haplotypes. Haplotype H5 is featured by a stop codon at position 67 . The relevance of these genetic modifications and haplotypes in venous thrombosis was evaluated in a case-control study including 1018 patients and 1018 age- and sex-matched controls. Surprisingly, the $\mathrm{H} 5$ haplotype was found in
$0.9 \%$ of controls, supporting that the Arg67Stop change is a low frequency nonsense polymorphism. The prevalence of this haplotype increased significantly in patients (3.0\%), one of whom was in a homozygous state. Multivariate analysis confirms that carriers have a 3.3-fold risk of developing venous thrombosis $(P=.002 ; 95 \% \mathrm{Cl}$ : 1.5-7.1). Moreover, we observed a significant association of this polymorphism with familial history of thrombosis $(P<.001)$. Our study supports that the ZPIArg67Stop nonsense polymorphism might be an indepen- dent genetic risk factor for venous thrombosis. This polymorphism has slightly lower prevalence but similar thrombotic risk than the FV Leiden or prothrombin 20210A. Although further studies are required, all available data support that the ZPI is a candidate to play a significant role in thrombosis and should be evaluated in thrombophilic studies. (Blood. 2006;108:177-183)

(C) 2006 by The American Society of Hematology

\section{Introduction}

Initially, venous thrombosis was considered a monogenic disease, as rare mutations affecting some anticoagulant proteins (antithrombin, protein $\mathrm{C}$, and protein $\mathrm{S}$ ) identified in thrombophilic families significantly increased (more than 8-fold) the risk for venous thrombosis. ${ }^{1}$ However, the consensus about the relevance in venous thrombosis of 2 polymorphisms (factor V Leiden and prothrombin 20210) supported that venous thrombosis is a multigenic disease. ${ }^{2}$ Accordingly, common genetic variations with mild associated risk could play a role in this disorder. ${ }^{2}$ Unfortunately, despite a considerable effort during 2 decades evaluating hundreds of polymorphisms affecting hemostatic proteins, no further genetic risk factors for venous thrombosis have been clearly identified. ${ }^{3}$ One possible explanation of these frustrating results is that the screening of candidate polymorphisms has been exclusively focused on classic hemostatic proteins. It would be interesting to evaluate further candidates that might play a role in hemostasis.

The precise role of the protein Z-dependent protease inhibitor (ZPI) is uncertain, but in vitro studies suggest that it might be a potent anticoagulant. Its name derives from the role that protein $\mathrm{Z}$ (PZ) plays in enhancing its function. ZPI is a $72-\mathrm{kDa}$ member of the serpin superfamily of serin protease inhibitors (SERPINA10) with tyrosine-serine as the $\mathrm{P} 1-\mathrm{P} 1{ }^{\prime}$ residues. ${ }^{4}$ Nevertheless, ZPI efficiently inhibits both factor Xa and factor XIa by 2 different mechanisms. ${ }^{5}$ In plasma, PZ completely complexes all ZPI. In the presence of procoagulant phospholipids and calcium, the PZ-ZPI complex produces rapid inhibition of factor Xa $\left(\mathrm{t}_{1 / 2}<10\right.$ seconds, at a rate 1000-fold faster than ZPI alone). ${ }^{5}$ Factor XIa inhibition by ZPI is not dependent on PZ, phospholipids, or calcium, but is enhanced by heparin. ${ }^{5}$ In contrast to other anticoagulant serpins, the inhibitory complex FXa-ZPI seems to be quite unstable, and the inactivation of FXIa also produced cleaved ZPI. Accordingly, the ZPI activity is consumed during the in vitro coagulation of plasma. ${ }^{5}$ A recent paper supports that the ZPI may be an unusual physiologic regulator of both the intrinsic FXase and the prothrombinase complexes. ${ }^{6}$ The possible relevance of this system in regulating the coagulation response and in thrombosis arises from the $P Z$ knock-out mice, which indicated that $\mathrm{PZ}$ appears to dampen the prothrombotic response. Moreover, the $P Z$-deficient mice exhibited prothrombotic tendency in combination with factor V Leiden. ${ }^{7}$ Recently, one nonsense mutation within the ZPI gene (Trp303Stop) was identified in $3.8 \%$ of patients with venous thrombosis but not in controls. $^{8}$ All of these data support a relevant role of this molecule in venous thrombosis. Therefore, this gene is a candidate to exhibit other genetic changes that might influence the risk of venous thrombosis.
From the Centro Regional de Hemodonación, Universidad de Murcia, Murcia, Spain; Unitat d'Hemostasia i Trombosi, Hospital de la Santa Creu i Sant Pau, Barcelona, Spain; Hematology Service, Hospital Clínico Universitario, Salamanca, Spain; and Hematology Service, Clínica Universitaria de Navarra, Pamplona, Spain.

Submitted August 11, 2005; accepted February 23, 2006. Prepublished online as Blood First Edition Paper, March 9, 2006; DOI 10.1182/blood-2005-08-3249.

Partially supported by Fundación Séneca (00583/PI/04); SAF2003-00840 and SAF2002-03499 (MCYT \& FEDER); the National Institutes of Health (HL70751); Fondo Investigación Sanitaria (FIS 02/0375 and RECAVA 03/01); Fundació "La Caixa"; and Fundació d'Investigació Sant Pau. J.C. and R.G.-C. are Investigadores Ramón y Cajal from the University of Murcia and the Spanish Ministry of Education and Science. J.M.S. was supported by FIS 99/3048 from the Fondo Investigación Sanitaria (Spanish Ministry of Health).

J.C. and R.G.-C. contributed equally to this work.

Reprints: Javier Corral, Centro Regional de Hemodonación, C/Ronda de Garay s/n, Murcia 30003, Spain; e-mail: javier.corral@ carm.es.

The publication costs of this article were defrayed in part by page charge payment. Therefore, and solely to indicate this fact, this article is hereby marked "advertisement" in accordance with 18 U.S.C. section 1734.

C) 2006 by The American Society of Hematology 


\section{Patients, materials, and methods}

\section{Patients and controls}

Our study included 1018 consecutive and unrelated white patients with a first, objectively confirmed episode of venous thromboembolism before the age of 75 years. These patients were enrolled from the files of the anticoagulation clinics in 4 hospitals in Spain: Hospital General Universitario (Murcia), Hospital de la Santa Creu i Sant Pau (Barcelona), Hospital Clínico Universitario (Salamanca), and Clínica Universitaria de Navarra (Pamplona). All cases were diagnosed appropriately by clinical probability, D-dimer levels, compression ultrasonography, ventilation perfusion lung scan, and, when necessary, phlebography or pulmonary angiography. Patients with known malignant disorders were excluded. The control group of our study included 1018 unrelated people without a history of vascular or thromboembolic disease. These controls were randomly selected among 2 sources: blood donors and traumatology and ophthalmology patients matched by age, sex, race, and geographic distribution with 1018 cases.

All included subjects gave their informed consent to enter the study, which was performed in accordance with the Declaration of Helsinki as amended in Edinburgh in 2000. Approval for this study was obtained from the institutional review boards of Hospital General Universitario (Murcia, Spain), the Hospital de la Santa Creu i Sant Pau (Barcelona, Spain), Hospital Clínico Universitario (Salamanca, Spain) and Clínica Universitaria de Navarra (Pamplona, Spain).

Demographic parameters (age and sex) were recorded in all subjects. Moreover, a list of other clinical data (familial history of venous thrombosis, recurrence, type of thrombotic event, location of the thrombosis, and other thrombotic risk factors such as use of oral contraceptives, hormone replacement therapy, phospholipid antibodies, and protein $\mathrm{C}$, protein $\mathrm{S}$, or antithrombin deficiency) were recorded.

\section{Genetic analysis}

Blood was collected from the antecubital vein into citrate tubes $(0.1$ volume $0.106 \mathrm{M}$ trisodium citrate), and genomic DNA was purified. Amplification of the 4 coding exons of the ZPI gene (exons 2-5) was performed by polymerase chain reaction (PCR) using the primers described by Van de Water et $\mathrm{al}^{8}{ }^{8}$ with minor modifications. The $1277 \mathrm{G}>\mathrm{A}$ (Gly250Ser) polymorphism was genotyped by single-strand conformation polymorphism (SSCP). The 1276C $>$ T (Tyr249) polymorphism was determined by SSCP and confirmed by PCR-ASRA using the RsaI enzyme. The 1438G $>$ A (Trp303Stop) mutation was evaluated by SSCP and PCR-allelic specific restriction assay (ASRA) with HinfI. The 603A $>$ G (Lys25Arg), 647A $>$ G (Ser40Gly), and 728C $>$ T (Arg67Stop) polymorphisms were evaluated by SSCP and PCR-ASRA with Eco130I, MspI, and SatI, respectively. Confirmation of the identified genotypes for all polymorphisms was performed by sequence analysis.

Moreover, the factor V $(F V)$ Leiden and prothrombin (PT) 20210G $>\mathrm{A}$ polymorphisms were determined in all patients and controls as described. ${ }^{9}$

\section{Statistical analysis}

Results are expressed as median value and interquartile ranges for continuous variables and as percentages for categoric variables. Univariate statistical analysis was performed by the chi-square test. The strength of the association of major risk factors and the polymorphism with the occurrence of disease was estimated by calculation of the odds ratio (OR) with EpiInfo software (Centers for Disease Control and Prevention, Atlanta, GA) and the Cornfield method for the calculation of $95 \%$ confidence intervals (CIs). ${ }^{10}$ Multivariate analysis was performed using logistic regression enter method, with the SPSS statistical package for Windows 8.0 software (Chicago, IL). Differences with a 2-tailed $P$ value less than .05 were considered statistically significant.

We tested the null hypothesis that Hardy-Weinberg equilibrium holds using the chi-square method. We calculated the $P$ value by simulation with 100000 replicates.
Linkage disequilibrium (LD) between each pair of SNPs was estimated by the pairwise correlation (r) among genotypes. Working with SNPs, this measure is equivalent to the correlation of Weir ${ }^{11}$ (Appendix A in Meng et al ${ }^{12}$ ).

Haplotype analysis with unrelated individuals has to face up to the problem of ambiguity of haplotypes; that is, many individuals are consistent with different haplotype configurations. We used the likelihood approach described previously to estimate the haplotypes..$^{13}$ This method, in addition to estimating haplotype frequencies, computes the posterior probabilities of the pairs of haplotypes that are consistent with the observed markers for each subject. Then, to evaluate the association of the affection status with haplotypes, we applied the score method that uses those posterior probabilities to account for haplotype ambiguities. ${ }^{14}$ Based on generalized linear models, this approach can be applied to binary, ordinal, and quantitative traits and, at the same time, allow adjustment for nongenetic covariates, which may be critical when analyzing genetic complex traits. In our case, we used $F V$ Leiden and PT as covariates.

All genetic calculations were done with the statistical environment $R$ (The R Project for Statistical Computing, http://www.r-project.org).

\section{Results}

\section{Identification of genetic variations in the ZPI gene}

In a previous study of our group, we evaluated the ZPI Trp303Stop mutation in 218 Spanish patients with venous thrombosis by PCR-ASRA and SSCP. No patient carried the Trp303Stop nonsense mutation. ${ }^{15}$ However, the SSCP analysis and ulterior sequence revealed 2 variations in the published sequence of $Z P I$ exon 3: $1276 \mathrm{C}>\mathrm{T}$ silent mutation $(\mathrm{Tyr} 249)$ and $1277 \mathrm{G}>\mathrm{A}$ point mutation, responsible for the Gly250Ser missense change (nucleotide and amino acid numbering as per mRNA GenBank entry AF181467) (Figure 1A). Of interest, these mutations are consecutive. The first modification, also identified by Van de Water et al, ${ }^{8}$ was recognized as a possible SNP in the NCBI SNPs database (ID: rs2232707). ${ }^{16}$ The second change was also identified in the New Zealand cohort, ${ }^{8}$ and it was present in 8 patients with venous thrombosis from our preliminary study. This change was also present in the NCBI SNPs database (ID: rs2232708). ${ }^{16}$

Additionally, we sequenced all coding exons of the ZPI gene (exons 2-5) of 5 carriers of the ZPI Gly250Ser polymorphism using primers and conditions previously reported. ${ }^{8}$ No subject had further genetic modifications on exons 3,4 , and 5 . However, we identified 3 genetic changes in the $5^{\prime}$-end of exon 2 (Figure 1B), a region homologous to that of another hemostatic serpin: heparin cofactor II, ${ }^{17}$ which encodes the acidic tail of the N-terminus of the ZPI molecule. All Gly250Ser carriers simultaneously had a 603A $>$ G transition (responsible for the Lys25Arg missense modification). Of interest, 4 subjects also had a $728 \mathrm{C}>\mathrm{T}$ point mutation, which causes a nonsense change (Arg67Stop) in heterozygous state. Finally, only one patient also had the 647A $>$ G (Ser40Gly) variation (Figure 1B). All of these modifications were also identified by Van de Water et $\mathrm{al}^{8}$ and are present in the NCBI SNPs database ID: Lys25Arg, rs941590; Arg67Stop, rs2232698; Ser40Gly, rs941591. ${ }^{16}$

Unfortunately, the frequency and the role in venous thrombosis of these genetic modifications were not clearly defined. Accordingly, we extensively evaluated these 5 SNPs and the Trp303Stop mutation of the ZPI gene on a large cohort of patients with venous thrombosis and controls.

\section{Case-control study}

Demographic, clinical, and genetic data of cases and controls are presented in Table 1 . These features did not significantly differ in the samples from the 4 hospitals (data not shown). 
A
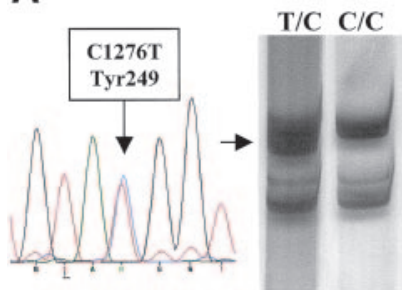

$\underline{\text { SSCP }}$

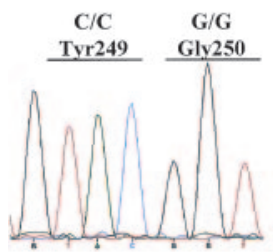

\section{Normal sequence}

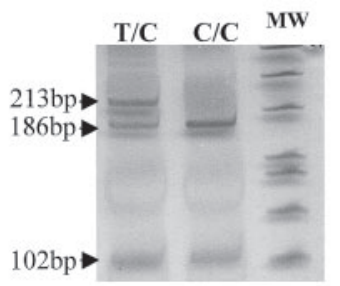

B
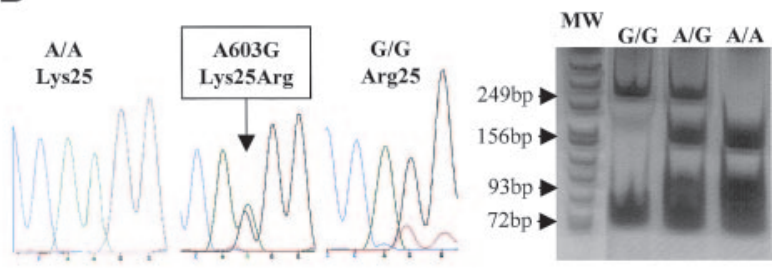

PCR-ASRA
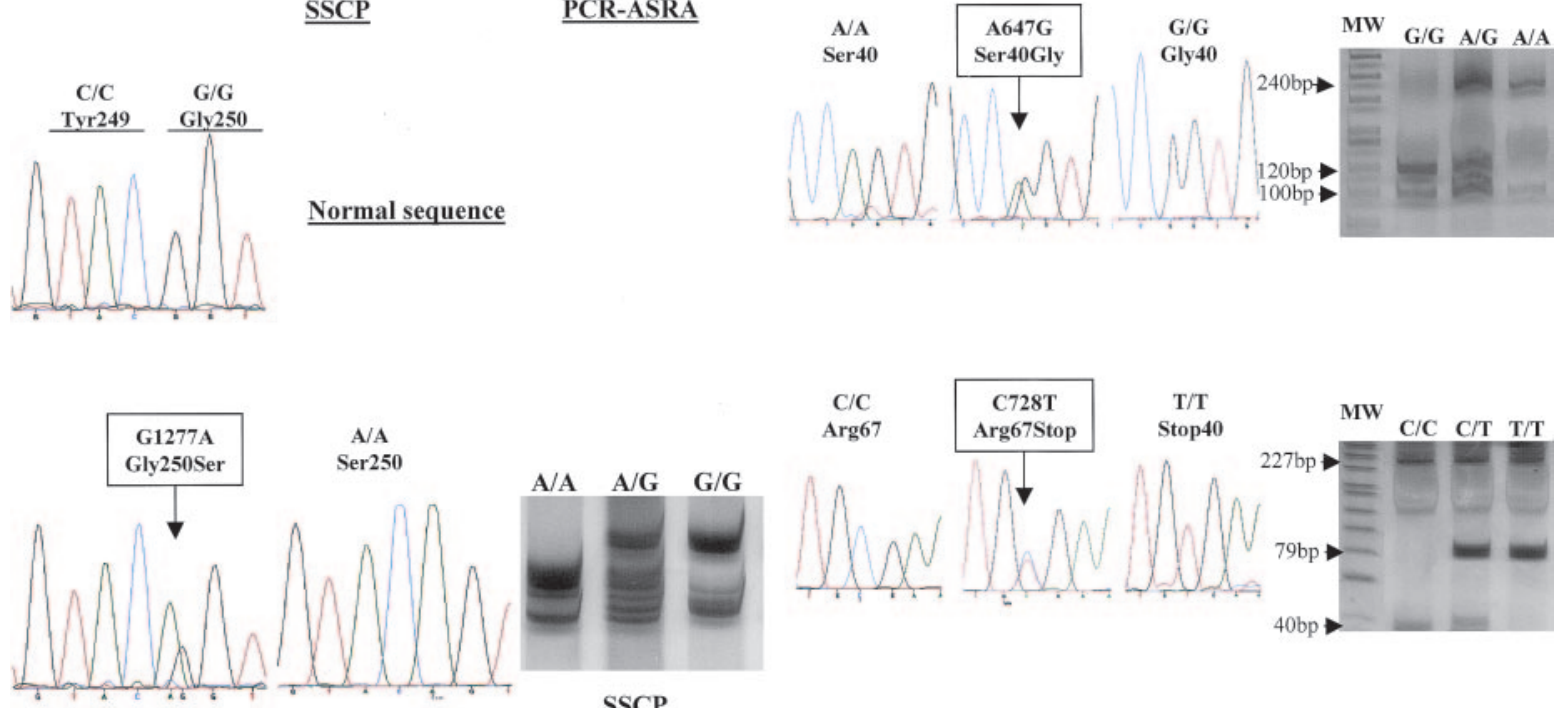

$\underline{\text { SSCP }}$

Figure 1. Identification of genetic variations in the ZPI encoding gene. (A) Variations in exon 3. (B) Variations in $5^{\prime}$-end of exon 2. MW indicates molecular weight marker ( $\phi$ X174 DNA/Hinfl Marker; Promega, Madison, WI).

The median age of patients at the time of the first thrombotic event was 45 years (interquartile ranges, 33-58), and the ratio of males to females was 1:1. Approximately two thirds of the patients suffered a single thrombotic episode (280 of 1018 had recurrent episodes of venous thrombosis). Moreover, 218 patients reported risk factors such as use of oral contraceptives, antiphospholipid antibodies, or hormone replacement therapy, and deficiency of antithrombin, protein C, or protein S. Finally, 177 patients (17.4\%) reported familial history of thrombosis.

The prevalence of the classic prothrombotic polymorphisms was similar to that described in other series. Thus, the $F V$ Leiden was present in 145 patients ( 3 in homozygous state; $14.2 \%$ ), and

Table 1. Characteristics of patients with venous thrombosis and control subjects

\begin{tabular}{|c|c|c|c|}
\hline & Patients & Control subjects & $P^{\star} ;$ OR $(95 \% \mathrm{Cl})$ \\
\hline $\mathrm{N}$ & 1018 & 1018 & \\
\hline Age, y (range) & $49(36-62)$ & $47(35-63)$ & .618 \\
\hline Male sex, no & 509 & 509 & .999 \\
\hline FV Leiden, no. & & & $<.001 ; 5.29(3.5-8.0)$ \\
\hline$-1-$ & 873 & 987 & \\
\hline$+/-\&+/+$ & $142 \& 3$ & $31 \& 0$ & \\
\hline PT 20210, no. & & & $<.001 ; 4.20(2.7-6.7)$ \\
\hline $\mathrm{G} / \mathrm{G}$ & 917 & 992 & \\
\hline$G / A \& A / A$ & $94 \& 7$ & $26 \& 0$ & \\
\hline ZPI 603 (Lys25Arg), no. & & & .113 \\
\hline $\mathrm{A} / \mathrm{A}$ & 295 & 328 & \\
\hline$A / G \& G / G$ & $522 \& 201$ & $525 \& 165$ & \\
\hline ZPI647 (Ser40Gly), no. & & & .959 \\
\hline $\mathrm{A} / \mathrm{A}$ & 759 & 758 & \\
\hline$A / G \& G / G$ & $246 \& 13$ & $249 \& 11$ & \\
\hline ZPI728 (Arg67Stop), no. & & & $<.001 ; 3.40(1.5-7.8)$ \\
\hline $\mathrm{C} / \mathrm{C}$ & 988 & 1009 & \\
\hline $\mathrm{C} / \mathrm{T} \& \mathrm{~T} / \mathrm{T}$ & $29 \& 1$ & $9 \& 0$ & \\
\hline ZPI 1277 (Gly250Ser), no. & & & $<.001 ; 3.01(1.6-5.8)$ \\
\hline $\mathrm{G} / \mathrm{G}$ & 977 & 1004 & \\
\hline$G / A \& A / A$ & $40 \& 1$ & $14 \& 0$ & \\
\hline
\end{tabular}

${ }^{*}$ Crude analysis; OR is given when $P<.05$. 
From bloodjournal.hematologylibrary.org by guest on July 17, 2014. For personal use only.

Table 2. Clinical features of patients according to the ZPI, FV Leiden and prothrombin polymorphisms

\begin{tabular}{|c|c|c|c|c|c|}
\hline & No. (\%) & $\begin{array}{c}\text { Age at first } \\
\text { episode, } y \text { (range) }\end{array}$ & $\begin{array}{c}\text { Recurrence, } \\
\text { no. (\%) }\end{array}$ & $\begin{array}{c}\text { Other risk } \\
\text { factors, no. (\%) }\end{array}$ & $\begin{array}{c}\text { Familial } \\
\text { history, no. (\%) }\end{array}$ \\
\hline \multicolumn{6}{|l|}{ ZPILys25Arg } \\
\hline Carrier & $723(71.0)$ & $45(33-58)$ & $203(68.8)$ & $164(22.7)$ & $138(19.1)$ \\
\hline Noncarrier & $295(29.0)$ & $47(33-60)$ & $77(26.1)$ & 54 (18.3) & $39(13.2)^{\star}$ \\
\hline \multicolumn{6}{|l|}{ ZPISer40Gly } \\
\hline Carrier & $259(25.4)$ & $45(33-56)$ & $70(27.0)$ & $58(22.4)$ & $38(14.7)$ \\
\hline Noncarrier & 759 (74.6) & $45(33-59)$ & $210(27.7)$ & $160(21.0)$ & 139 (18.3) \\
\hline \multicolumn{6}{|c|}{ ZPI Arg67Stop } \\
\hline Carrier & $30(2.9)$ & $49(37-63)$ & $11(36.7)$ & 9 (33.3) & $11(40.0)$ \\
\hline Noncarrier & $988(97.1)$ & $45(33-58)$ & $269(27.2)$ & 209 (21.2) & $166(16.8) \dagger$ \\
\hline \multicolumn{6}{|c|}{ ZPIGly250Ser } \\
\hline Carrier & $41(4.0)$ & $49(33-63)$ & $11(29.3)$ & $10(26.8)$ & $14(36.6)$ \\
\hline Noncarrier & $977(96.0)$ & $45(33-58)$ & $269(27.5)$ & 208 (21.3) & $163(16.7) \dagger$ \\
\hline \multicolumn{6}{|l|}{ FV Leiden } \\
\hline Carrier & $145(14.2)$ & $44(30-56)$ & $42(29.0)$ & $31(21.4)$ & $30(20.7)$ \\
\hline Noncarrier & $873(85.8)$ & $45(33-59)$ & $238(27.3)$ & $187(21.4)$ & $147(16.8)$ \\
\hline \multicolumn{6}{|l|}{ PT 20210A } \\
\hline Carrier & 101 (9.9) & $45(32-56)$ & $22(21.8)$ & $21(20.8)$ & $16(15.8)$ \\
\hline Noncarrier & $917(90.1)$ & $45(33-59)$ & $258(28.1)$ & $197(21.5)$ & $161(17.6)$ \\
\hline
\end{tabular}

${ }^{\star} P<.05$.

$\dagger P<.005$.

the PT 20210A allele was identified in 101 patients (7 in homozygous state; $9.9 \%$ ) (Table 1 ). Controls had a significantly lower prevalence of these prothrombotic polymorphisms: 31 (3.0\%) were heterozygous for the $F V$ Leiden and 26 (2.6\%), for the PT 20210A allele (Table 1). Accordingly, these polymorphisms increased 5.3-fold ( $F V$ Leiden) and 4.2-fold (PT 20210A) the risk of venous thrombosis $(P<.001 ; 95 \% \mathrm{CI}: 3.5-8.0$ and $P<.001$; 95\% CI: 2.7-6.7, respectively). The age of the first episode of venous thrombosis, the percentage of recurrence, the incidence of additional risk factors, and the history of familial thrombosis associated with these polymorphisms are shown in Table 2.

In our study, no patient or control carried the ZPI Trp303Stop mutation.

The ZPI 1276C $>$ T silent mutation (Tyr249) was identified in only one patient with venous thrombosis. This patient suffered from an idiopathic deep venous thrombosis at the age of 58 years and reported no familial history of thrombosis. This mutation was not identified in controls.

The prevalence of other ZPI polymorphisms $(1277 \mathrm{G}>\mathrm{A}$ [Gly250Ser]; 603A $>$ G [Lys25Arg]; 647A $>$ G [Ser40Gly]) in patients and controls is reported in Table 1.

Finally, the $Z P I 728 \mathrm{C}>\mathrm{T}$ transition, responsible for a nonsense change (Arg67Stop), has to be considered as a low prevalence polymorphism as it was identified in heterozygous state in 9 controls $(0.9 \%)$. Of interest, this nonsense polymorphism was more frequent among patients with venous thrombosis (3.0\%, Table 1). Remarkably, one patient was homozygous for this nonsense variation (Figure 1B). This patient suffered the first episode of deep venous thrombosis at the age of 62 years when she was under hormone replacement therapy, and reported familial history of thrombosis. According to our results, this polymorphism increased 3.4-fold the risk of venous thrombosis $(P<.001$; 95\% CI: 1.5-7.8) (Table 1).

The clinical features of carriers and noncarriers of these polymorphisms are shown in Table 2. No significant differences were observed when attending to the age of the first episode, recurrence, presence of additional risk factors, or familial history of venous thrombosis for all tested polymorphisms except an in- creased familial history of venous thrombosis among carriers of the ZPI Lys25Arg, Arg67Stop, and Gly250Ser variants (Table 2).

The allele and genotype frequencies for the present study are consistent with that predicted by Hardy-Weinberg equilibrium (data not shown).

\section{ZPI haplotypes}

Our results supported strong linkage disequilibrium between 4 polymorphisms of the $Z P I$ gene $(603 \mathrm{~A}>\mathrm{G}, 647 \mathrm{~A}>\mathrm{G}, 728 \mathrm{C}>\mathrm{T}$, and $1277 \mathrm{G}>\mathrm{A}$ ) (Table 3 ) that defined 5 different haplotypes (Figure 2). The most common haplotype, with an overall frequency of 0.58 in controls, was wild type at all 4 loci (H1: 603A, 647A, $728 \mathrm{C}$, and $1277 \mathrm{G}$ ) (Figure 2). All other haplotypes shared the $603 \mathrm{G}$ variant. Of interest, haplotype $\mathrm{H} 5$ had the $728 \mathrm{~T}$ and $1277 \mathrm{~A}$ variations. One patient had an H5-variant haplotype (H5v), probably caused by recombination. Figure 2 also suggests a model that might explain the origin of these haplotypes.

The distribution of haplotypes in patients and controls is reported in Table 4. The estimated haplotype frequencies are also shown in Table 4 . We point out that the haplotype $\mathrm{H} 5$ was the only one showing a prevalence statistically higher in patients than in controls (Table 4).

Table 3. Linkage disequilibrium between each pair of ZPISNPs in cases and controls

\begin{tabular}{lccccr}
\hline & FV Leiden & ZPI603 & ZPI647 & ZPI728 & ZPI1277 \\
\hline Patients & & & & & \\
PT & -0.01 & 0.00 & -0.01 & 0.01 & 0.01 \\
FVLeiden & NA & -0.03 & 0.00 & 0.01 & 0.04 \\
ZPI603 & NA & NA & 0.40 & 0.13 & 0.18 \\
ZPI647 & NA & NA & NA & -0.06 & -0.05 \\
ZPI728 & NA & NA & NA & NA & 0.83 \\
Controls & & & & & \\
PT & -0.03 & 0.04 & -0.03 & -0.02 & -0.02 \\
FVLeiden & NA & -0.00 & -0.00 & -0.02 & -0.02 \\
ZPI603 & NA & NA & 0.41 & 0.08 & 0.09 \\
ZPI647 & NA & NA & NA & -0.003 & -0.05 \\
ZPI728 & NA & NA & NA & NA & 0.80 \\
\hline
\end{tabular}

NA indicates not applicable. 
Figure 2. ZPI haplotypes identified in this study and a suggested model that explains the origin of these haplotypes.

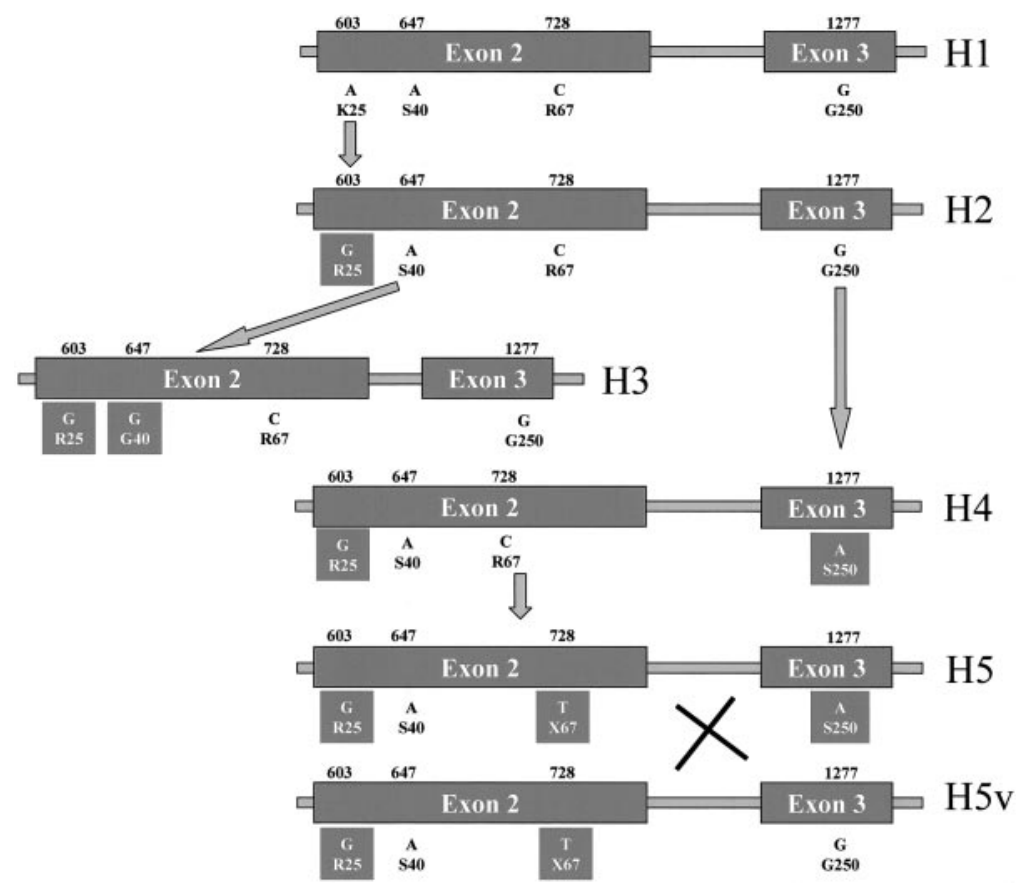

The score test for association of traits with haplotypes allows the introduction of covariates in the model. ${ }^{14}$ We use $F V$ Leiden and $P T$ as covariates. Moreover, the score statistic takes into account the uncertainty in the imputation of haplotypes to unrelated individuals. The result of this test suggests a clear association between the haplotypes and the disease $(P=.002)$.

Multivariate analysis including the 2 classic prothrombotic polymorphisms ( $F V$ Leiden and $P T 20210 \mathrm{G}>\mathrm{A}$ ) confirmed that the $Z P I$ H5 haplotype is an independent risk factor for venous thrombosis $(P=.002)$. The risk of venous thrombosis associated with the ZPI H5 haplotype (ie, the risk of the nonsense ZPI Arg67Stop polymorphism) is slightly lower than that of $F V$ Leiden or prothrombin $20210 \mathrm{G}>\mathrm{A}$ polymorphisms $(\mathrm{OR}=3.32,95 \% \mathrm{CI}$ : 1.5-7.1; OR $=5.32,95 \%$ CI: 3.6-7.9; OR $=4.24,95 \%$ CI: 2.7-6.6, respectively).

Table 4. Distribution of ZPI haplotypes among patients with venous thrombosis and control subjects

\begin{tabular}{ccc}
\hline & $\begin{array}{c}\text { Patients, no. } \\
\text { (\% or frequency) }\end{array}$ & $\begin{array}{c}\text { Controls, no. } \\
\text { (\% or frequency) }\end{array}$ \\
\hline H1/H1 (reference group) & $297(29.2)$ & $328(32.2)$ \\
H1/H2 & $337(33.1)$ & $334(32.8)$ \\
H1/H3 & $163(16.0)$ & $182(17.9)$ \\
H1/H4 & $3(0.3)$ & $4(0.4)$ \\
H1/H5 \& H1/H5v & $17 \& 1(1.8)$ & $5(0.5)^{*}$ \\
H2/H2 & $90(8.8)$ & $83(8.1)$ \\
H2/H3 & $77(7.6)$ & $66(6.5)$ \\
H2/H4 & $5(0.5)$ & $1(0.1)$ \\
H2/H5 & $9(0.9)$ & $3(0.3)$ \\
H3/H3 & $13(1.3)$ & $11(1.1)$ \\
H3/H4 & $3(0.3)$ & 0 \\
H3/H5 & $2(0.2)$ & $1(0.1)$ \\
H5/H5 & $1(0.1)$ & 0 \\
H1 (reference group) & $1115(0.546)$ & $1181(0.580)$ \\
H2 & $608(0.299)$ & $570(0.280)$ \\
H3 & $271(0.134)$ & $271(0.133)$ \\
H4 & $11(0.006)$ & $5(0.003)$ \\
H5 \& H5v & $30 \& 1(0.015 \& 0.0005)$ & $9 \& 0(0.004)^{*}$ \\
\hline
\end{tabular}

${ }^{*}$ Statistical comparison versus reference group $P<.01$.
The clinical features of patients according to their ZPI haplotype are shown in Table 5. Statistical comparison with carriers of the common $\mathrm{H} 1$ haplotype in homozygous state (reference group) found that the $\mathrm{H} 5$ and $\mathrm{H} 2$ haplotypes were associated with familial history of thrombosis $(P<.001)$ (Table 5).

Finally, no control simultaneously carried the ZPI H5 haplotype and $F V$ Leiden or prothrombin polymorphisms, but 9 patients did (4 patients carried the ZPI Arg67Stop and the prothrombin 20210A variants [0.4\%], and 5 patients presented simultaneously the ZPI Arg67Stop and the $F V$ Leiden polymorphisms [0.5\%]). Similarly, the simultaneous presence of $F V$ Leiden and prothrombin variants was identified in 14 patients (1.4\%) but not in the controls.

\section{Discussion}

The members of the serpin superfamily of serine protease inhibitors share a conserved structure and use a unique suicide substratelike inhibitory mechanism. Serpins differ from other protease inhibitors in that they undergo a profound change in topology in order to entrap their target protease in an irreversible complex. This extremely efficient mechanism explains the selection of the serpins to control the proteolytic cascades of higher organisms. Thus, serpins have a central role in controlling proteinases in many biologic pathways such as fibrinolysis, inflammation, complement activation, apoptosis, angiogenesis, and blood coagulation. ${ }^{18}$ Unfortunately, the molecular flexibility of serpins also renders these molecules susceptible to even minor factors (genetic or environmental) that cause dysfunction, by different mechanisms. ${ }^{19}$ Thus, the same serpins that are crucial for a normal physiologic function could also be involved in diseases. Multiple serpins play a significant role in the hemostatic system: PAI-1, PAI-2, PCI, heparin cofactor II, $\alpha 2$-antiplasmin, and antithrombin. Mutations affecting some of these molecules, especially antithrombin, have been identified in patients with thrombosis. ${ }^{20}$ The ZPI could be a new serpin to be included in the list of key molecules of the hemostatic system. This molecule plays a significant anticoagulant role as it potently inhibits FXa and FXIa. ${ }^{5,6}$ Accordingly, impaired 
From bloodjournal.hematologylibrary.org by guest on July 17, 2014. For personal use only.

Table 5. Clinical features of patients according to the ZPI haplotypes

\begin{tabular}{|c|c|c|c|c|c|}
\hline & No. & $\begin{array}{l}\text { Age first episode, } y, \\
\text { median (range) }\end{array}$ & $\begin{array}{l}\text { Recurrence, } \\
\text { no. (\%) }\end{array}$ & $\begin{array}{c}\text { Other risk } \\
\text { factors, no. (\%) }\end{array}$ & $\begin{array}{c}\text { Familial } \\
\text { history, no. (\%) }\end{array}$ \\
\hline $\mathrm{H} 1 / \mathrm{H} 1$ (reference group) & 297 & $46(36-60)$ & 77 (25.9) & $54(18.2)$ & $40(13.5)$ \\
\hline $\mathrm{H} 1 / \mathrm{H} 2$ & 337 & $45(32-58)$ & $95(28.2)$ & 77 (22.8) & $69(20.5)$ \\
\hline $\mathrm{H} 1 / \mathrm{H} 3$ & 163 & $45(32-56)$ & $46(28.2)$ & $42(25.8)$ & $21(12.9)$ \\
\hline $\mathrm{H} 1 / \mathrm{H} 4$ & 3 & $21(18-65)$ & 0 & 0 & 0 \\
\hline$H 1 / H 5 \&$ H1/H5v & $17 \& 1$ & 47 (32-62) & $3(16.7)$ & $7(38.9)^{\star}$ & $7(38.9)^{\star}$ \\
\hline $\mathrm{H} 2 / \mathrm{H} 2$ & 90 & $43(33-59)$ & $28(31.1)$ & $21(23.3)$ & $20(22.2)^{*}$ \\
\hline $\mathrm{H} 2 / \mathrm{H} 3$ & 77 & $45(34-53)$ & 19 (24.7) & $13(16.9)$ & $12(15.6)$ \\
\hline $\mathrm{H} 2 / \mathrm{H} 4$ & 5 & $53(36-67)$ & 0 & 0 & $1(20.0)$ \\
\hline $\mathrm{H} 2 / \mathrm{H} 5$ & 9 & $50(38-65)$ & $5(55.6)$ & $1(11.1)$ & $2(22.2)$ \\
\hline $\mathrm{H} 3 / \mathrm{H} 3$ & 13 & $41(28-61)$ & $4(30.8)$ & $2(15.4)$ & $1(7.7)$ \\
\hline $\mathrm{H} 3 / \mathrm{H} 4$ & 3 & $29(25-62)$ & 0 & $1(33.3)$ & $2(66.7)$ \\
\hline $\mathrm{H} 3 / \mathrm{H} 5$ & 2 & $57(50-65)$ & $2(100)$ & 0 & $1(50.0)$ \\
\hline $\mathrm{H} 5 / \mathrm{H} 5$ & 1 & 62 & $1(100)$ & 0 & $1(100)$ \\
\hline \multicolumn{6}{|l|}{ Haplotype carrier } \\
\hline $\mathrm{H} 2$ & 608 & $45(33-58)$ & $147(28.4)$ & $111(21.4)$ & $104(20.1)^{\star}$ \\
\hline $\mathrm{H} 3$ & 271 & $45(32-56)$ & $71(27.5)$ & $58(22.5)$ & 37 (14.3) \\
\hline $\mathrm{H} 4$ & 11 & $44(25-64)$ & 0 & $1(9.1)$ & $3(27.3)$ \\
\hline $\mathrm{H} 5$ \& H5v & 31 & $46(32-62)$ & $11(36.7)$ & $9(30.0)$ & $11(36.7) \dagger$ \\
\hline
\end{tabular}

${ }^{*} P<.05$.

$\dagger P<.001$.

function or reduced levels of ZPI might increase the risk of thrombosis. Thus, deficiency of its cofactor PZ seems to increase the risk of thrombosis. ${ }^{7}$ Moreover, the PZ/ZPI system is impaired by antiphospholipid antibodies, increasing the thrombotic risk of patients with this autoimmune disease. ${ }^{21}$ A recent report identifies nonsense mutations in the ZPI gene that significantly increase the risk of venous thrombosis. ${ }^{8}$ Our results further support the relevance of this serpin on hemostasis and identify a genetic risk factor for venous thrombosis. The results of this case-control study suggest that the ZPI H5 haplotype, featured by a stop codon at position 67, might be an independent risk factor for venous thrombosis. The prevalence of the ZPI Arg67Stop polymorphism is slightly lower than that of the $F V$ Leiden or $P T 20210 \mathrm{G}>\mathrm{A}$, but the associated risk is similar. Moreover, this polymorphism is associated with familial history of thrombosis. Our data support that the ZPI Arg67Stop polymorphism could be included in the list of markers of thrombophilia. The study performed in New Zealand also identified this polymorphism. ${ }^{8}$ However, further studies in other populations are required to confirm the thrombotic role of the ZPI Arg67Stop nonsense polymorphism. Another limitation of this study derives from the inclusion of patients with recurrence, which could produce a biased estimate of venous thromboembolic risk. The optimal design to assess recurrences is a prospective study after a first event. We have reanalyzed all the data considering only patients with a single episode of thrombosis $(n=738)$. This group was matched for age, race, and sex with controls, and the results were equivalent (multivariate analysis: $F V$ Leiden: $P<.001$ $[\mathrm{OR}=5.54,95 \%$ CI: 3.4-9.0]; $P$ T 20210G $>$ A: $P<.001$ [OR $=5.37,95 \% \mathrm{CI}: 3.1-9.3]$; and ZPI Arg67Stop: $P=.011$ $[\mathrm{OR}=3.35,95 \% \mathrm{CI}: 1.3-8.6])$.

All available information supports a relatively high incidence of nonsense mutations in the $Z P I$ gene among patients with venous thrombosis: $4.4 \%$ in New Zealand population ${ }^{8}$ and 3.0\% in Spanish population. Accordingly, genetic modifications causing premature stop codons in the ZPI (polymorphisms or mutations) will probably increase the risk of venous thrombosis. The functional consequence of these nonsense mutations seems obvious. The stop codon, especially that located in the N-terminus region of the protein (position 67), should cause circulating deficiency of this serpin.
Certainly, it is necessary to determine the levels of ZPI in carriers of these nonsense modifications to confirm such suggestion, but the expected ZPI deficiency of these patients might explain the increased risk of venous thrombosis. However, these results are partially conflictive with the recent report of the Leiden Thrombophilia Study (LETS). ${ }^{22}$ This study did not detect a relationship between the plasmatic level of $Z P I$ and venous thrombosis. ${ }^{22}$ This apparent discrepancy might be explained by the relatively low frequency of nonsense changes (probably $<4 \%$ in the LETS study), most of them in heterozygous state. Thus, the normal levels of ZPI in noncarriers of the ZPI Arg67Stop polymorphism or the Trp303Stop mutation might mask any possible moderate deficiency of ZPI associated with this polymorphism in heterozygous state.

Our study identifies a nonsense polymorphism. Although it might seem that a genetic change causing a stop mutation never would have been evolutionary selected, there are old and recent references of this process. First, the origin of a stop codon might provide an evolutionary advantage that explains its selection. Thus, the common Arg577Stop nonsense polymorphism of the ACTN3 gene has a beneficial effect on the function of skeletal muscle in generating forceful contractions at high velocity, increasing sprint performance, ${ }^{23}$ or a stop codon polymorphism of Toll-like receptor 5 is associated with resistance to systemic lupus erythematosus. ${ }^{24}$ Other nonsense polymorphisms, such as the Tyr319Stop polymorphism of the SLC6A18 gene, ${ }^{25}$ have no significant relevance. In contrast, there are examples of nonsense polymorphisms associating with different pathologies. Thus, the frequency of the 446G $>$ T (Trp149Stop) polymorphism of the ARLTS1, a member of the ADP ribosylation family, was similar in controls and patients with sporadic tumors but was significantly more common among patients with familial cancer. ${ }^{26}$ Finally, the common nonsense polymorphism affecting the complement $C 9$ gene (Arg95Stop), which is present in $6.7 \%$ of the Japanese population, ${ }^{27}$ causes complement deficiency when present in homozygous state. Other polymorphisms affecting serpin-encoding genes might cause deficiency of the affected protein. The best example is the deficiency of $\alpha 1$-antitrypsin associated with the $\mathrm{Z}$ variant (Glu342Lys), which associates with emphysema and liver cirrhosis in homozygous 
state. ${ }^{28}$ To the best of our knowledge, the ZPI Arg67Stop is the first nonsense polymorphism identified in serpins that increases the risk of venous thrombosis in heterozygous state.

Finally, we identified the first case homozygous for a nonsense mutation in the ZPI gene. Certainly, this patient suffered from recurrent venous thrombosis, but the first episode was quite late (at 62 years old) and there were additional risk factors present (hormone replacement therapy). Moreover, the carrier has no additional pathologies. The features of this ZPI knock-out patient are similar to that described for another anticoagulant serpin that shares additional structural similarities with the ZPI, the heparin cofactor II. Our group also identified the first case with heparin cofactor II homozygous deficiency that has no significant pathologic consequences. ${ }^{29}$ In contrast, complete antithrombin deficiency is associated with embryonic lethality in mice and humans. ${ }^{30}$ All of these data support that many serpins are not necessary for embryo development, but they are necessary to the control of serine proteases in the adult life. Moreover, an important redundancy between different serpins and other inhibitory mechanisms should exist to explain the absence of significant pathologies under complete deficiency of some serpins such as ZPI or heparin cofactor II.
In conclusion, our results support that the ZPI Arg67Stop nonsense polymorphism might be considered as a mild genetic risk factor for venous thrombosis. This polymorphism has lower prevalence but similar risk than the $F V$ Leiden or prothrombin 20210A variants (ORs 3.32, 5.32, and 4.23, respectively). All available data support that the ZPI is a good candidate to play a significant role in thrombosis. Other genetic changes affecting this serpin, including other polymorphisms or unusual mutations, might be present in some of the so far idiopathic thrombosis, and consequently, functional and genetic analysis of the ZPI would be performed in thrombophilic studies.

\section{Acknowledgments}

The authors thank Dr Juan A. Iniesta (Neurology Service, Hospital Reina Sofia, Murcia, Spain) for the collection of samples and clinical data; Nuria Garcia Barberá and Adriana Ordoñez (Universidad de Murcia) for genotyping; and Alfonso Buil (Hospital de la Santa Creu i Sant Pau, Barcelona) for statistical analysis.

\section{References}

1. Franco RF, Reitsma PH. Genetic risk factors of venous thrombosis. Hum Genet. 2001;109:369384.

2. Zoller B, Garcia de Frutos P, Hillarp A, Dahlback B. Thrombophilia as a multigenic disease. Haematologica. 1999;84:59-70.

3. Lane DA, Grant PJ. Role of hemostatic gene polymorphisms in venous and arterial thrombotic disease. Blood. 2000;95:1517-1532.

4. Han X, Huang ZF, Fiehler R, Broze GJ Jr. The protein Z-dependent protease inhibitor is a serpin. Biochemistry. 1999;38:11073-11078.

5. Han X, Fiehler R, Broze GJ Jr. Characterization of the protein Z-dependent protease inhibitor. Blood. 2000;96:3049-3055.

6. Heeb MJ, Cabral KM, Ruan L. Down-regulation of factor IXa in the factor Xase complex by protein Z-dependent protease inhibitor. J Biol Chem. 2005;280:33819-33825.

7. Yin ZF, Huang ZF, Cui J, et al. Prothrombotic phenotype of protein $Z$ deficiency. Proc Natl Acad Sci U S A. 2000;97:6734-6738.

8. Van de Water N, Tan T, Ashton F, et al. Mutations within the protein Z-dependent protease inhibitor gene are associated with venous thromboembolic disease: a new form of thrombophilia. $\mathrm{Br} \mathrm{J}$ Haematol. 2004;127:190-194.

9. Corral J, Zuazu-Jausoro I, Rivera J, GonzalezConejero R, Ferrer F, Vicente V. Clinical and anaIytical relevance of the combination of prothrombin 20210A/A and factor V Leiden: results from a large family. Br J Haematol. 1999;105:560-563.

10. Cornfield J. A method of estimating comparative rates from clinical data: applications to cancer of the lung, breast, and cervix. J Natl Cancer Inst. 1951;11:1269-1275.

11. Weir BS. Genetic Data Analysis II. Sunderland, MA: Sinauer Associates; 1996.

12. Meng Z, Zaykin DV, Xu CF, Wagner M, Ehm MG Selection of genetic markers for association anal- ysis using linkage disequilibrium and haplotypes. Am J Hum Genet. 2003:73:115-130.

13. Zhao JH, Lissarrague S, Essioux L, Sham PC. GENECOUNTING: haplotype analysis with missing genotypes. Bioinformatics. 2002;18:16941695.

14. Schaid DJ, Rowland CM, Tines DE, Jacobson RM, Poland GA. Score tests for association between traits and haplotypes when linkage phase is ambiguous. Am J Hum Genet. 2002;70:425434.

15. Gonzalez-Conejero R, Perez-Ceballos E, Vicente V, Corral J. Protein Z-dependent protease inhibitor W303X mutation in venous thrombosis. $\mathrm{Br} \mathrm{J}$ Haematol. 2005;129:561-562.

16. National Center for Biotechnology Information Single Nucleotide Polymorphisms database. http://www.ncbi.nlm.nih.gov/projects/SNP/index.html. Accessed January 31, 2006.

17. Baglin TP, Carrell RW, Church FC, Esmon CT, Huntington JA. Crystal structures of native and thrombin-complexed heparin cofactor II reveal a multistep allosteric mechanism. Proc Natl Acad Sci U S A. 2002;99:11079-11084.

18. Silverman GA, Bird PI, Carrell RW, et al. The serpins are an expanding superfamily of structurally similar but functionally diverse proteins: evolution, mechanism of inhibition, novel functions, and a revised nomenclature. J Biol Chem. 2001; 276:33293-33296.

19. Carrell R, Corral J. What can Drosophila tell us about serpins, thrombosis and dementia? Bioessays. 2004;26:1-5.

20. Corral J, Vicente V, Carrell RW. Thrombosis as a conformational disease. Haematologica. 2005; 90:238-246

21. Forastiero RR, Martinuzzo ME, Lu L, Broze GJ. Autoimmune antiphospholipid antibodies impair the inhibition of activated factor $X$ by protein Z/protein Z-dependent protease inhibitor. J Thromb Haemost. 2003;1:1764-1770.
22. Al-Shanqeeti $A$, van Hylckama Vlieg A, Berntorp E, Rosendaal FR, Broze GJ Jr. Protein Z and protein Z-dependent protease inhibitor: determinants of levels and risk of venous thrombosis. Thromb Haemost. 2005;93:411-413.

23. Yang N, MacArthur DG, Gulbin JP, et al. ACTN3 genotype is associated with human elite athletic performance. Am J Hum Genet. 2003;73:627631.

24. Hawn TR, Wu H, Grossman JM, Hahn BH, Tsao BP, Aderem A. A stop codon polymorphism of Tolllike receptor 5 is associated with resistance to systemic lupus erythematosus. Proc Natl Acad Sci U S A. 2005;102:10593-10597.

25. Eslami B, Kinboshi M, Inoue S, Harada K, Inoue K, Koizumi A. A nonsense polymorphism (Y319X) of the solute carrier family 6 member 18 (SLC6A18) gene is not associated with hypertension and blood pressure in Japanese. Tohoku J Exp Med. 2006;208:25-31.

26. Calin GA, Trapasso F, Shimizu M, et al. Familial cancer associated with a polymorphism in ARLTS1. N Engl J Med. 2005;352:1667-1676.

27. Kira R, Ihara K, Watanabe K, et al. Molecular epidemiology of C9 deficiency heterozygotes with an Arg95Stop mutation of the C9 gene in Japan. J Hum Genet. 1999;44:109-111.

28. Carrell RW, Lomas DA. Alpha1-antitrypsin deficiency: a model for conformational diseases. N Engl J Med. 2002;346:45-53.

29. Corral J, Aznar J, Gonzalez-Conejero R, et al. Homozygous deficiency of heparin cofactor II: relevance of $\mathrm{P} 17$ glutamate residue in serpins, relationship with conformational diseases, and role in thrombosis. Circulation. 2004;110:13031307.

30. Ishiguro K, Kojima T, Kadomatsu K, et al. Complete antithrombin deficiency in mice results in embryonic lethality. J Clin Invest. 2000;106:873878. 